\title{
Improving the Overall Equipment Effectiveness (OEE) of Drum Testing Machine in Laboratory of Tire Manufacturing Using FMEA and PFMEA
}

\author{
Prince Sibarani \\ Master of Mechanical Enginering \\ Swiss German University \\ Tangerang- Banten Indonesia \\ prince.sibarani@student.sgu.ac.id
}

\author{
Tanika D Sofianti \\ Master of Industrial Engineering \\ Swiss German University \\ Tangerang- Banten Indonesia \\ tanika.sofianti@sgu.ac.id
}

\author{
Aditya T Pratama \\ Master of Industrial Engineering \\ Swiss German University \\ Tangerang- Banten Indonesia \\ aditya.pratama@sgu.ac.id
}

\begin{abstract}
Drum testing is equipment to test tire capability in the highway prototype in the tire company. Overall Equipment Effectiveness (OEE) is used to measure the productivity of the equipment. $O E E$ has declined and has not achieved the target from Jun 2019 until June 2020.

The objectives of this research are to determine the fixed parameter in the OEE calculation at the Drum Testing and to increase the $\mathrm{OEE}$ for achieving the company target. Process Failure Mode Effects Analysis (PFMEA) and Failure Mode Effects Analysis (FMEA) help to identify potential failure mode and its consequences, and formulate a solution to achieve the OEE target by improving the drum testing machine. Furthermore, an ideal target should be customized based on the manufacturing year and brand of the machine. This research showed PFMEA and FMEA successfully improve the OEE efficiency for five machines increases the average $O E E$ from $53.6 \%$ to $67.2 \%$.
\end{abstract}

Keywords: overall equipment effectiveness (OEE), failure mode effect analysis (FMEA), process failure mode effect analysis (PFMEA), drum testing machine, risk priority number $(\mathrm{RPN})$.

\section{INTRODUCTION}

Tires are an important part of a motorized vehicle that functions to continue power push and braking, control direction, as well as support the load and speed of vehicles load. Based on the function of the tire, it is necessary to have performance test tires. The tire performance test is a national and international requirement testing for a critical item where a tire is installed in the vehicle must be completely safe to use and run for both high speed and endurance. It is very necessary to test the performance of the tire so that the tire can fulfill its function [4].

A drum testing machine is an instrument in the form of a steel wheel with a smooth surface and a diameter of 1707 $\mathrm{mm}$ and a minimum width equal to the total width of the tire. There are 3 types testing tire performance of drum testing as follows:
1. High-speed Test (constant load test with increasing speed)

2. Endurance Test (constant speed test with increasing Load)

3. Long Run (Bead durability with low speed and max load)

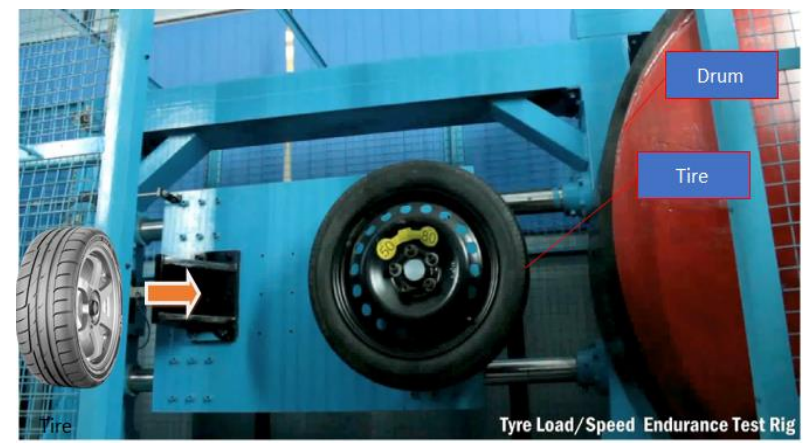

Fig. 1. Drum testing machine

Fig.1 a drum testing machine consisting of drums and tires. The Drum test is a tool or machine drum-shaped with a diameter of $1,707 \mathrm{~mm}$ and has surface as a prototype of the highway in Laboratory indoors condition

\section{LITERATURE REVIEW}

This section explains the study theory that is relevant to the research as follows:

- Overall Equipment Effectiveness (OEE), Failure Mode Effect Analysis (FMEA), Process Failure Mode Effect Analysis (PFMEA), Ishikawa diagram, Autonomous Maintenance and tire testing methods.

- Thus provide a strong background for this research, Fig. 2 shows the mind map of this research. 


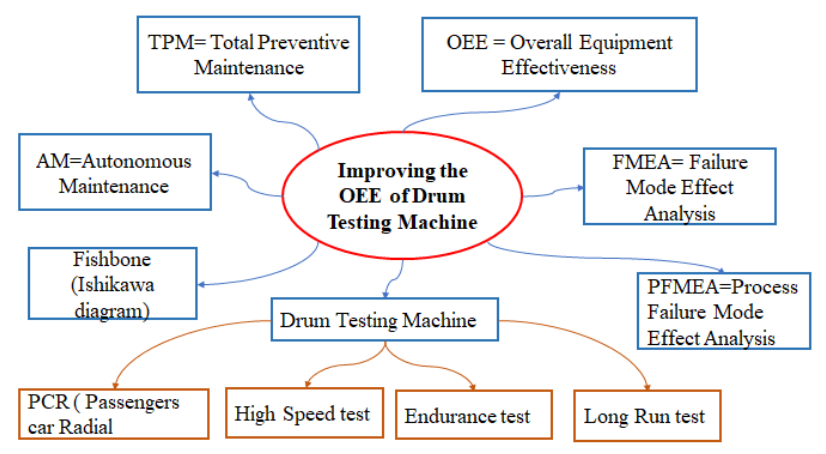

Fig. 2. Literature review mind map

\section{A. Overall Equipment Effectiveness (OEE)}

Overall Equipment Effectiveness (OEE) is measuring productivity and effectiveness and identifies equipment potential, tracking loss and improvement opportunity. The OEE result is an indicator of the performance of TPM [9].

Overall Equipment Effectiveness (OEE) is a good method to measure the performance of the machine and conducted observation, with an analysis fish-bone diagram. The results of OEE can be used to propose a suitable corrective action. Therefore, OOE really suits manufacturing process environment that requires reliable machinery [6].

OEE (Overall Equipment Effectiveness) is the best way to find out the extent to which a machine is effectively used by considering Availability, Performance, and Quality. The results can be compare between machine and between manufacturing in different Machine, division, departments, industries and service testing [12].

The results of objective OEE are: 1) Increase Efficiency 2) 3) Increase lifetime machine 4) Decrease backlog testing 5) Reduce cost 6) Increase Profit.

The component of OEE is Availability, Performance, and Quality and the formula for calculations is [12]. Equation 1 Formula of OEE:

$$
\% \text { OEE }=\% \text { Availability } x \% \text { Performance } x \% \text { Quality }
$$

\section{B. Process Failure Mode and Effect Analysis (PFMEA)}

Process Failure Mode and Effects Analysis (PFMEA) is a type of FMEA, which purpose to identify potential failure factors in the production process as well as preventive measures to ensure product quality by detecting the severity, probability occurrence and failure detection, trying to improve product quality [2].

\section{Failure Mode and Effect Analysis (FMEA)}

Failure Mode and Effect Analysis is a method used to prevent errors that may occur in the future and an engineering technique used to determine, identify and eliminate known Potential failures, Failure effects, Failure causes, or Failure errors, from the system or design and service process before the failure reaches the customer. It is the system approach and mental discipline that an engineer normally goes in any based on experience [11] FMEA is a systematic technique for finding the problem, measuring Severity, Occurrence and Detection to get the value of Risk Priority Number (RPN), evaluating, and assessing potential problems or failures from design to process before the problems occur.

FMEA is one of the Core Tools contained in international standards for the automotive industry such as IATF 16949 and a quality tool that is widely applied in the automotive, aviation, and electronic semiconductor firms to eliminate potential problem even before a product is mass production [8]. in 1949 the proactive approach was developed first implemented by the United States Army in the 1970s. FMEA is one of the Six Sigma tools to identify the source or cause of a quality problem. According to Chrysler (1995), FMEA can be done by:

1) Recognizing and evaluating the potential failure of a product and knowing the impact that would occur if there was a failure. 2) Identify actions that can eliminate or reduce the likelihood of potential failure occurring. 3)Process documents

The steps to the identification of FMEA can be describe as follows [1]: 1) Identification of critical machine functions 2) Identification of potential failure modes 3) Identification of Failure Effects 4) Identification of Failure causes 5) Define value Severity, Occurrence and Detection 6) Calculate Risk Priority number (RPN) .

The next step is more on the evaluation of maintenance measures. This is important, because any improvement that conducted can be planned using previous maintenance activities. This action can eliminate redundant action plans so that maintenance is more effective. A risk priority number (RPN) is calculated for each failure mode. The RPN is obtained by multiplying the severity rating (S), the likelihood of occurrence $(\mathrm{O})$, and the likelihood of detection (D) obtained in the previous step. Given that all ratings are drawn in the interval 1 to 10 , the three factors are considered to have equal weight in the RPN score.

RPN calculation is expressed as below [1] Equation.2 Formula of RPN:

$R P N_{i}=\sum_{i=1}^{n} S_{i} x O_{i} \times D_{i}=1,2,3 \ldots n$

RPN : Risk Priority number, S : Severity, O: Occurrence D: Detection

Comparison of the features of the proposed and previous models. the number of research articles About OEE studies where almost all papers can identify the source of the big loss of each process on Availability, Performance and Quality and also determine the calculation of OEE [7], [10]. 
The decision to use the PFMEA and FMEA method in this research is based on the research article that is closest to the research paper [2], [3], [5] where in this paper it is clearly described how to identify and prioritize potential failures in the production process can to identify paremeter Severity, Occurrence and Detection and get Suggested solutions to reduce or eliminate manufacturing process failures [3], [5],[1],[9]. FMEA is one of a systematic system method for failure highly structured for failure analysis which at the time of implementation shows successful results of increasing OEE because this method can analyze failures at the design, in process when has been mass production. This method can directly lead to the Risk Priority number (RPN) value defined as the product of Severity (S), occurrence (O), and Detection (D) failure corrective action should be taken.

\section{RESEARCH METHOLOGY}

This research uses primary data and secondary data, The Primary data are taken from Documents and records that carried out by collecting data from Tire Testing laboratory and Engineering Department. Data consists of on how the OEE calculation method is currently being carried out, whether all the items for the calculation have been covered, what is the biggest factor causing the decrease in OEE, and what are the general corrective actions taken in case of damage and how to setup the machine.

The secondary data are from observations to ensure that the data obtained is valid and real and can be calculated. Observations were made at the beginning of the sampling process, rim preparation, tire testing preparation, maintenance schedule implementation, length of downtime and setup, and repair time in the event of a machine failure.

\section{A. Flow chart of Research Methodology}

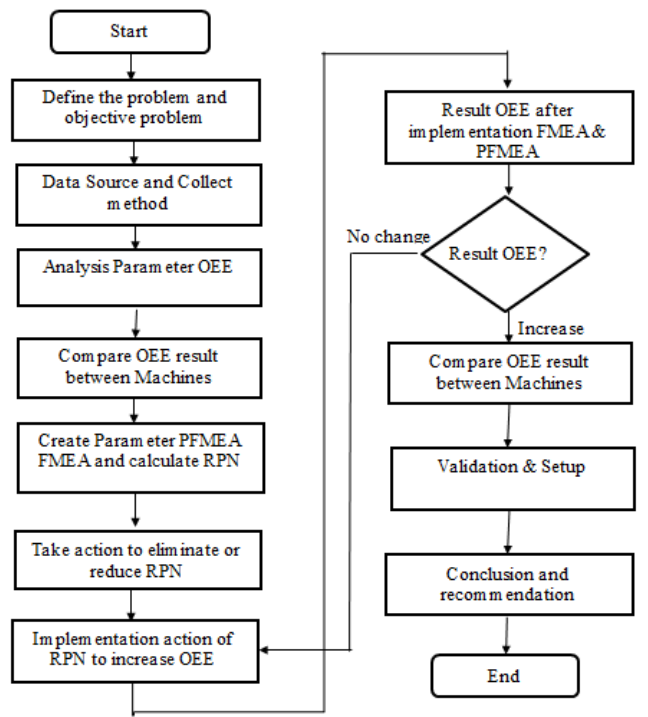

Fig. 3. Research methodology
The flow chart research methodology is shown in Fig. 3 with the following steps.

\section{RESULT AND ANALYSIS}

This section provides the result of calculating the result OEE before review and after review, result develop FMEA and PMEA and the result of the implementation of FMEA and to answer the research problems, research questions.

\section{A. OEE Calculation}

Analysis after the review resulted in changes of placement and calculation of OEE

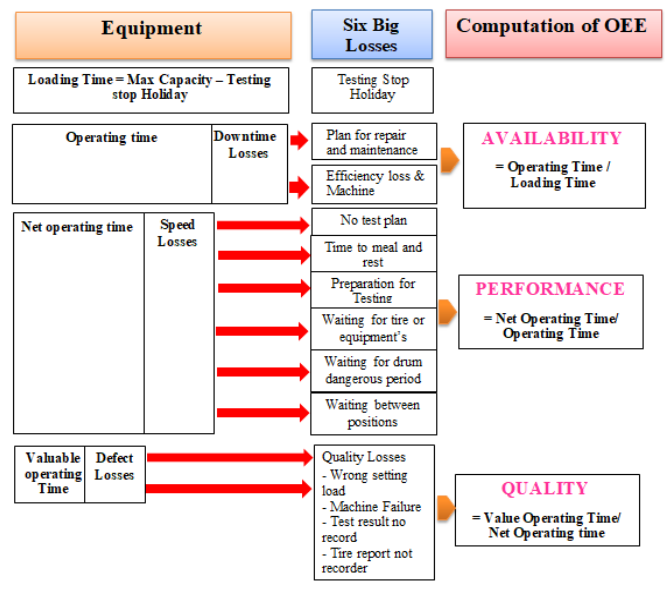

Fig.4 OEE Item Calculation

The source of the OEE calculation is from Six Big Losses and is depicted in Fig.4 Big Losses consists of 1) Testing stop holiday 2) Plan for repair and maintenance 3) Efficiency loss \& machine validation 4) No test plan 5) Time to meal and rest 6) Preparing for testing 7) Waiting for the tire or equipment 8) Waiting for drum testing dangerous 9) Waiting between positions 10) Quality Losses

\section{B. Analysis Ishikawa of Diagram OEE}

In the Ishikawa of Diagram at Fig 5, it can be seen that there are three dominant factors that influence the achievement of OEE: Machine, Material and Man.

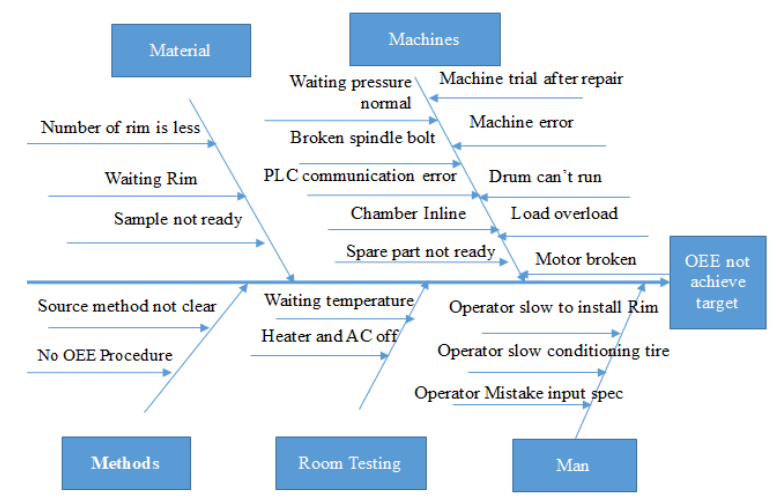

Fig.5 Analysis Ishikawa diagram of availability 
In the machine factor, the machine is often damaged then it needs maintenance, for the human factor, operator skills are still lacking while the material factor is raw materials/spare parts are often not available.

\section{Flow of PFMEA \& FMEA}

Process Failure Mode and Effects Analysis (PFMEA) is a type of FMEA, which identifies the potential failure factors in the production and assembly process, uses a methodological logic to identify the failure rate of the product in the production process and seeks to correct the failures in processes [2].

PFMEA determines testing requirements and weaknesses in the testing process, either based on experience on the previous testing or from external testing. There are the important when to define DFMEA as follows:

1) Set special characteristics on testing that have an impact on safety, functions, and government regulations. 2) Identification of historical problems with internal testing or external testing.

FMEA defines requirement item or Function: Hazardous- No warning, with warning, classification downtime effect Very high until Low. There are the steps as follows:

1. Determine the process requirements at each stage of the Drum Testing process. The goal is to determine the characteristics according to product requirements or environmental requirements or safety requirements. 2) Identify the potential failures in the process to meet requirements. 3) Determine the effect of potential failure on requirements. 4) Assign Severity ranking for each effect mode (S), Occurrence (O), Detection (D) and Calculation Severity, Occurrence \& Detection. 5) Calculate RPN (Risk priority number). 6) Apply Corrective action for improvement RPN to reduce High and Very-High risk Failure mode.

\section{Analysis $O E E$}

The results of OEE, Availability, Performance, and Quality of the five machines can be seen in Table 1.

TABLE 1.

REVIEW OEE

\begin{tabular}{ccccc}
\hline Machine & $\begin{array}{c}\text { Average } \\
\text { availability }\end{array}$ & $\begin{array}{c}\text { Average } \\
\text { Performance }\end{array}$ & $\begin{array}{c}\text { Average } \\
\text { Quality }\end{array}$ & OEE \\
\hline DDT1 & $95.5 \%$ & $30.8 \%$ & $95.5 \%$ & $28.2 \%$ \\
DDT2 & $96.9 \%$ & $74.1 \%$ & $96.7 \%$ & $70.0 \%$ \\
DDT3 & $93.5 \%$ & $82.1 \%$ & $99.1 \%$ & $76.1 \%$ \\
DDT4 & $78.1 \%$ & $77.8 \%$ & $96.0 \%$ & $57.6 \%$ \\
DDT5 & $70.1 \%$ & $54.9 \%$ & $95.3 \%$ & $36.1 \%$ \\
\hline
\end{tabular}

The availability factor of DDT4 and DDT5 machines are still less productive and the performance factors for
DDT1 and DDT5 are still less than optimal, while in the Quality factor there are problems on DDT1, DDT2, DDT4 and DDT5 machines.

\section{E. Process Failure Mode Effect Analysis (PFMEA) for Drum Testing}

The process from scheduling to the end of the report creation process and starting Process \& Function, Requirements, Potential Failure Mode, Potential effects of Failure, Potential Cause (s)/Mechanism (s) of Failure, Current Process Control Prevention, Current Process Control Detection were determined by the team member and determining the value of Severity, Occurrence \& Detection to get the RPN value for all processes and determine the category that needs to be done. Recommended Action and Responsibility \& Completion for RPN: 101-150: Inherent Risk: High, Action Plan: Eliminated, mitigated, transferred and RPN: $\geq 151$ : Inherent Risk: Very High, Action Plan: Eliminated, mitigated, transferred

TABLE 2 .

PROCESS FAILURE MODE AND EFFECT ANALYSIS

\begin{tabular}{|c|c|c|c|c|c|c|c|}
\hline $\begin{array}{l}N \\
0\end{array}$ & $\begin{array}{l}\text { Item / } \\
\text { Function }\end{array}$ & $\begin{array}{l}\text { Potential Failure } \\
\text { Mode }\end{array}$ & $\begin{array}{l}\text { Potential } \\
\text { effects of } \\
\text { Failure }\end{array}$ & SOD & RPN & Cat & Recommended Action \\
\hline 1 & $\begin{array}{l}\text { Make } \\
\text { schedule } \\
\text { Testing }\end{array}$ & $\begin{array}{l}\text { Sample tire not } \\
\text { asper regular } \\
\text { surveillance rule }\end{array}$ & $\begin{array}{l}\text { Unachieve } \\
d \text { target }\end{array}$ & 228 & 32 & L & $\begin{array}{l}\text { Make automatic system to } \\
\text { link schedule PPC to } \\
\text { schedule taken sample }\end{array}$ \\
\hline 2 & $\begin{array}{l}\text { Take sample } \\
\text { from Final } \\
\text { Inspection }\end{array}$ & $\begin{array}{l}\text { Sample tire not } \\
\text { as per } \\
\text { surveillance } \\
\text { schedule } \\
\end{array}$ & $\begin{array}{l}\text { Loss time } \\
\text { and cost }\end{array}$ & 238 & 48 & $\mathrm{~L}$ & $\begin{array}{l}\text { Install \& implementation } \\
\text { barcode systemin Lab }\end{array}$ \\
\hline 3 & $\begin{array}{l}\text { Install tire to } \\
\text { rim }\end{array}$ & $\begin{array}{l}\text { Rim usage not } \\
\text { according } \\
\text { standard }\end{array}$ & $\begin{array}{l}\text { Quality } \\
\text { loss }\end{array}$ & 728 & 112 & $\mathrm{H}$ & $\begin{array}{l}\text { Install \& implementation } \\
\text { barcode system in Lab }\end{array}$ \\
\hline 4 & $\begin{array}{l}\text { Conditioning } \\
\text { tire }\end{array}$ & $\begin{array}{l}\text { Conditioning } \\
\text { time not } \\
\text { according } \\
\text { standard }\end{array}$ & $\begin{array}{l}\text { Quality } \\
\text { loss }\end{array}$ & 728 & 112 & $\mathrm{H}$ & $\begin{array}{l}\text { Separate condition room } \\
\text { identities start condition time } \\
\text { in tires }\end{array}$ \\
\hline 5 & $\begin{array}{l}\text { Check } \\
\text { Pressure }\end{array}$ & $\begin{array}{l}\text { Air pressure } \\
\text { usage is not } \\
\text { according to the } \\
\text { standard }\end{array}$ & $\begin{array}{l}\text { Quality } \\
\text { loss }\end{array}$ & 726 & 84 & $\mathrm{M}$ & $\begin{array}{l}\text { order automatic pressure in } \\
\text { machine testing Install } \\
\text { automatic pressure in } \\
\text { machine }\end{array}$ \\
\hline 6 & Testing Tire & $\begin{array}{l}\text { Indoor testing } \\
\text { not accordingto } \\
\text { the procedure } \\
\text { and test method }\end{array}$ & $\begin{array}{l}\text { Wrong } \\
\text { Judgment }\end{array}$ & 128 & 112 & $\mathrm{H}$ & $\begin{array}{l}\text { Input list value with program } \\
\text { computer Choice the } \\
\text { program parameter settingin } \\
\text { computermachine }\end{array}$ \\
\hline 7 & $\begin{array}{l}\text { Uninstall } \mathrm{rm} \\
\text { from tire }\end{array}$ & Testing delayed & $\begin{array}{l}\text { Loss time } \\
\text { and cost }\end{array}$ & 543 & 60 & $\mathrm{M}$ & $\begin{array}{l}\text { Separated the place for the } \\
\text { tires that have finished the } \\
\text { test it easier to monitor the } \\
\text { uninstall rim }\end{array}$ \\
\hline 8 & Make Report & $\begin{array}{l}\text { Incorrect entry } \\
\text { data }\end{array}$ & $\begin{array}{l}\text { Quality } \\
\text { loss }\end{array}$ & 428 & 64 & $\mathrm{M}$ & $\begin{array}{l}\text { Create an automatic print out } \\
\text { report from the machine }\end{array}$ \\
\hline
\end{tabular}

In Table 2. described Process Failure Mode and Effect Analysis in point 3 , the problem with installing tire to rim is caused by the rim that is not used standard and the corrective action taken is to ensure the operator to ensure that the spec database and standard are in accordance, the preventive is the use of a barcode system in the laboratory. Point 4 item conditioning time is caused by the operator not understanding how to test procedures, the improvement is to provide retraining to operators and verify all test methods used on tires.

Point 6 item testing tire is caused by mistake inputting data on the computer, the improvement is to ensure that the parameter settings are correct and re-verify to avoid a mistakes, the prevention is that all test items are available on the computer therefore the operator only chooses the spec according to the test. 


\section{F. Failure Mode Effect Analysis (FMEA) for Drum Testing}

The analysis results that can be obtained from the agreement consists of several members who formulate FMEA for a drum testing machine and this has become a mutual agreement from determining the Item / Function, Potential Failure Mode, Failure effects, Failure Causes and determining the value of Severity, Occurrence, Detection and determination of the RPN value and the categories that should be corrected.

Recommended Action for RPN: 200-300: Inherent Risk: High, Action Plan: Eliminated, mitigated, transferred and RPN: $\geq 301$ : Inherent Risk: Very High, Action Plan: Eliminated, mitigated, transferred.

TABLE 3.

LIST FMEA CATEGORY VERY-HIGH AND HIGH OF RPN

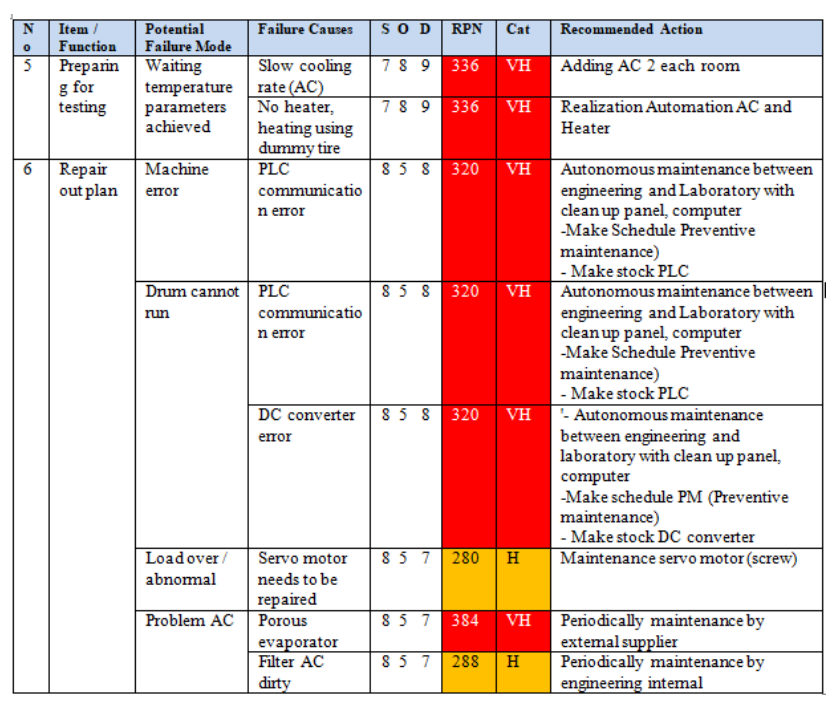

In Table 3. FMEA Drum Testing describes it can be seen that there are several items that have a low RPN to the highest RPN which are made in the L (Low), M (Medium), $\mathrm{H}$ (High), VH (Very High) categories. This will contribute directly to the machine process itself, especially in the $\mathrm{H} \&$ $\mathrm{VH}$ category. Because of this, the categories $\mathrm{H}$ and $\mathrm{VH}$ must be able to solve each problem so that it can optimize engine performance. For the Low and Medium categories, it remains a priority for improvement after $\mathrm{H}$ and $\mathrm{VH}$ are resolved

\section{G. Result of OEE after PFMEA \& FMEA Implementation}

The OEE results after the implementation of the FMEA and DFMEA methods showed a significant result, the improvements made have an impact on the productivity and efficiency of the company.
TABLE 4.

OEE AFTER IMPLEMENTATION FMEA

\begin{tabular}{ccccccc}
\hline $\begin{array}{c}\text { MC } \\
\text { No }\end{array}$ & A & P & Q & OEE AI & OEE BI & OEE Delta \\
\hline DDT1 & $96.1 \%$ & $36.2 \%$ & $96.5 \%$ & $33.6 \%$ & $28.2 \%$ & $5.3 \%$ \\
DDT2 & $99.0 \%$ & $89.8 \%$ & $98.5 \%$ & $87.6 \%$ & $70.0 \%$ & $17.6 \%$ \\
DDT3 & $100.0 \%$ & $85.8 \%$ & $99.1 \%$ & $85.0 \%$ & $76.1 \%$ & $8.9 \%$ \\
DDT4 & $100.0 \%$ & $85.0 \%$ & $95.9 \%$ & $81.5 \%$ & $57.6 \%$ & $23.9 \%$ \\
DDT5 & $72.4 \%$ & $69.1 \%$ & $97.0 \%$ & $48.6 \%$ & $36.1 \%$ & $12.4 \%$ \\
\hline Avg & & & & & & $13.6 \%$ \\
\hline
\end{tabular}

A : Availability, P : Performance, Q: Quality

OEE AI : OEE after Implementation FMEA

OEE BI : OEE before Implementation and after review

OEE Delta: OEE Increase after Implementation FMEA

The percentage of increase in OEE after implementation is measured by each machine is shown in Table 4.

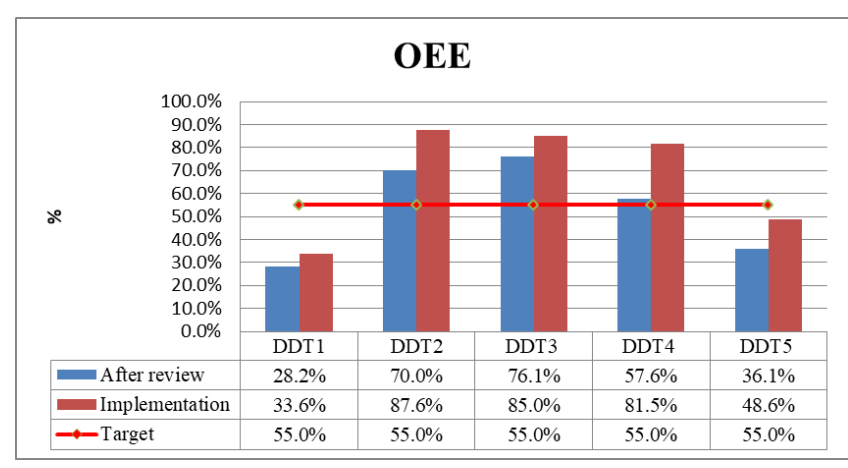

Fig. 6. Chart OEE after implementation FMEA

In Fig 6 shows the percentage of increase in OEE after implementation and from the overall implementation there has been an increase in each machine.

\section{CONCLUSION AND RECOMMENDATION}

OEE is powerful indicator to measure the effectiveness of the machine drum testing and influenced based on three important parameters which are; Availability (A), Performance (P), and Quality (Q) and using FMEA and PFMEA method with improvement maintenance performance, Autonomous maintenance.

\section{A. Conclusions}

This research showed PFMEA and FMEA successfully improve the OEE efficiency for five machines increases DDT1 is $5,3 \%$, DDT2 is 17,6 , DDT3 is $8.9 \%$, DDT4 is $23,9 \%$, DDT5 is $12.4 \%$ and an average increase of $13.6 \%$ so that the average OEE from $53.6 \%$ to $67.2 \%$ and reduces the cost of external testing and reduces the testing backlog. the analysis that has been done is as follows:

Material must be preparation materials and machines according schedule testing, Machines needed maintenance 
with preventive maintenance and autonomous maintenance are periodically so that machine performance can be optimal. Besides that, there is a need for parts that are critical parts and consumable parts so that they can reduce downtime machine. Man the routine training is needed to further improve operator performance, Method need periodical reviews regarding SOPs and procedures to facilitate drum testing operations. Drum test room need maintenance of the AC and heater is necessary as well as routine cleanliness of the evaporator and filter so that the temperature in the drum test room is always in good condition. Spare part needs to provide spare part stock.

The advantage of this method is that it can see the events that will occur so that it requires consistency and compliance from all parties, operators, superiors, Engineering and management, especially in providing the necessary spare parts. It is expected that all personnel can consciously carry out Autonomous maintenances, calibrations, speed up the un-assembly of rim from tires, following schedule, work procedures and instructions with discipline.

This research has merit compared to the reference which is that this research leads directly to the drum testing machine at the tire manufacturing so that it can be implemented in the same industry.

\section{B. Recommendations}

OEE target is made in accordance to production manufacturing that based on the similarity on machine type or brand for each machine Evaluation and control of periodic implementation will have an impact on the efficiency and productivity of the Company.

Evaluation and control of periodic implementation will have an impact on the efficiency and productivity of the Company.

To set the new target OEE each DDT1, DDT2, DDT3, DDT4, DDT5 referring to the difference of improvement. example change target from $55 \%$ to $65 \%$ for DDT1 \& DDT5 by preparing the required spare part to achieve the overall average of OEE.

Considering the current condition which is in economic crisis due to Covid 19 pandemic, purchasing new machine is the least priority of the top management. However, when the company's financial health gets better, purchasing new machine to support the activities in Tire Testing Laboratory will be an option, and it will be started by feasibility study of the new machine procurement.

\section{ACKNOWLEDGMENT}

The author would like to express his sincere gratitude to GT Engineering teams, GT Laboratory Tire Performance teams for their collaboration in this work.

\section{REFERENCES}

[1] H. A. Samat, S. Kamaruddin, and I. A. Azid, "Integration of overall equipment effectiveness (OEE) and reliability method for measuring machine effectiveness," South African Journal of Industrial Engineering, 23 (1), pp. 92-113, 2012. https://doi.org/10.7166/23$1-222$

[2] M. Baghbani, S. Iranzadeh, and M. B. Khajeh, "Investigating the relationship between RPN parameters in fuzzy PFMEA and OEE in a sugar factory," Journal of Loss Prevention in the Process Industries, $60 \quad$ (April), pp. 221-232, 2019. https://doi.org/10.1016/j.jlp.2019.05.003

[3] K. E. Chong, K. C. Ng, and G. G. G. Goh, "Improving Overall Equipment Effectiveness (OEE) through integration of Maintenance Failure Mode and Effect Analysis (maintenance-FMEA) in a semiconductor manufacturer: A case study," IEEE International Conference on Industrial Engineering and Engineering Management, 2016-Janua (August 2016), pp. 1427-1431, 2016. https://doi.org/10.1109/IEEM.2015.7385883

[4] Y. Handoyo, "Analisis performance ban dengan alat drum test," Jurnal Ilmiah Teknik Mesin Unisma “45” Bekasi, 2 (1), pp. 98103 , 2014.

[5] Z. F. Hunusalela, S. Perdana, and R. Usman, "Analysis of productivity improvement in hard disc spare parts production machines based on OEE, FMEA, and fuzzy value in Batam," IOP Conference Series: Materials Science and Engineering, 508 (1), 2019. https://doi.org/10.1088/1757-899X/508/1/012086

[6] N. C. Maideen, S. Sahudin, N. H. M. Yahya, and A. O. Norliawati, "Practical Framework: Implementing OEE Method in Manufacturing Process Environment," IOP Conference Series: Materials Science and Engineering, 114 (1), 2016. https://doi.org/10.1088/1757-899X/114/1/012093

[7] P. Muchiri and L. Pintelon, "Performance measurement using overall equipment effectiveness (OEE): Literature review and practical application discussion," International Journal of Production Research, 46 (13), pp. 3517-3535, 2008. https://doi.org/10.1080/00207540601142645

[8] M. A. Musa, N. I. Kasim, A. R. Razali, Mahadzir, and W. A. N. W. Saidin, "Improvement of overall equipment effectiveness (OEE) through implementation of autonomous maintenance in crankcase line," Applied Mechanics and Materials, 761, pp. 165-169, 2015. https://doi.org/10.4028/www.scientific.net/amm.761.165

[9] I. S. Muthalib, M. Rusman, and G. L. Griseldis, "Overall Equipment Effectiveness (OEE) analysis and Failure Mode and Effect Analysis (FMEA) on Packer Machines for minimizing the Six Big Losses-A cement industry case," IOP Conference Series: Materials Science and Engineering, 885 (1), 2020. https://doi.org/10.1088/1757899X/885/1/012061

[10] Y. Ngadiman, B. Hussin, and I. A. Majid, "Exploring Overall Equipment Efficiency Model of Laboratory Capital Equipments in Malaysian Public Universities," Edulearn11: 3Rd International Conference on Education and New Learning Technologies, pp. 4769-4773, 2011.

[11] R. Nurcahyo, M. Faisal, M. Dachyar, and M. Habiburrahman, "Overall Equipment Effectiveness (OEE) at the laboratory of structure testing," Proceedings of the International Conference on Industrial Engineering and Operations Management, 2018-March, pp. 1080-1090, 2018.

[12] D. H. Stamatis, “The OEE primer: Understanding overall equipment effectiveness, reliability, and maintainability," In The Oee Primer: Understanding Overall Equipment Effectiveness, Reliability, and Maintainability, 2017. https://doi.org/10.1201/EBK1439814062 